Çocuk hastada bilateral mandibular kondil kırığı ve tedavisi: Bir Olgu Sunumu

\section{A bilateral mandibular condylar fracture in a child pa- tient: A Case Report}

\section{Dr. Öğr. Üyesi Gökhan Gürler}

İstanbul Medipol Üniversitesi, Diş Hekimliği Fakültesi, Ağız Diş Ve Çene Cerrahisi A.D., İstanbul

\section{Prof. Dr. Cağrı Delilbașı}

İstanbul Medipol Üniversitesi, Diş Hekimliği Fakültesi, Ağız Diş Ve Çene Cerrahisi A.D., İstanbul

\section{Dr. Emine Öğüt}

Îstanbul Medipol Üniversitesi, Diş Hekimliği Fakültesi, Ağız Diş Ve Çene Cerrahisi A.D., İstanbul

Geliș tarihi: 31 Ekim 2017

Kabul tarihi: 12 Aralık 2017

doi: 10.5505/yeditepe.2018.08769

\section{Yazışma adresi:}

Dr. Öğr. Üyesi Gökhan Gürler

İstanbul Medipol Üniversitesi, Diş Hekimliği Fakültesi, Unkapani, Atatürk Bulvari, No: 27 Fatih 34083

İstanbul - Türkiye

Tel: 02124534940

E-posta: ggurler@medipol.edu.tr
ÖZET

Mandibula kondil kırıkları ciddi komplikasyonlara neden olabilen maksillofasiyal yaralanmalardır. Kesin bir tedavi yöntemi olmayıp farklı parametreler ve cerrahların kişisel tecrübeleri açık veya kapalı yöntemlerin tercih edilmesinde belirleyicidir. Özellikle çocuk hastalarda kapalı yöntem, açık yönteme oranla daha çok tercih edilmektedir. Bu olgu sunumunda, düşme sonrası kliniğimize başvuran 4 yaşındaki kız çocuğunda tespit edilen izole bilateral mediale deplase subkondiler kırığın, ok luzyonu yükseltilmis Essix plak ve elastikler yardımıyla tedavisi ele alındı. Erken dönemde uygulanan fizik tedavi ve 4 hafta süresince yapılan haftalık kontrollerde Essix plağın posterior oklüzal yüzeyinin kademeli olarak aşındırılmasıyla normal okluzyon sağlandı. Düzenli aralıklarla yapılan 3,5 yıllık takipte herhangi bir komplikasyon, gelişim bozukluğu veya çene hareketlerinde problem gözlemlenmedi.

Anahtar kelimeler: Mandibula, kondil kırığı, çocuk, konservatif tedavi

\section{SUMMARY}

Mandibular condyle fractures are maxillofacial injuries that can cause serious complications. There is not a definite treatment modality, but the different parameters and the experience of the surgeon determine the choice of open or closed methods. Especially in pediatric patients, closed method is more preferred than open method. In this case report, the treatment of isolated bilateral medially displaced subchondral fracture with an Essix plate with increased posterior occlusion and elastics in a 4-year-old girl who admitted to our clinic after fall was discussed. Early occlusion was provided by early physical therapy and gradually grinding the posterior occlusal surface of the Essix plate at weekly controls during 4 weeks. There was no complication, developmental disability, or jaw movement problems at 3.5-year follow-up at regular intervals. Key words: Mandibula, condyle fracture, child, conservative treatment

\section{Giriş}

Maksillofasiyal kırıklar çocuklarda erişkinlere göre daha nadir görülmektedir. ${ }^{1,2}$ Gelişmekte olan mandibulada kansellöz kemik oranının yüksek olmasının getirmiş olduğu elastik yapı ve çocukların ailelerin gözetiminde olup çevreden korunması gibi etkenler çocuklarda daha az kırık görülmesini açıklamaktadır. ${ }^{3}$ Pediatrik fasiyal kırıkların büyük kısmını (\%20-50) mandibula kırıkları oluşturmaktadır ve mandibulada en sık kondil kırığına rastlanmaktadır.'

Çocuklarda kondil kırıklarının etyolojisi ve kırık oluşma şekli de yetişkinlere göre farklııklar göstermektedir. Yetişkinlerde trafik kazaları fasiyal kırıkların birincil nedeni olmaktayken, çocuklarda en önemli etyolojik faktör düşmeyle meydana gelen travmadır. ${ }^{4}$ Özellikle okula başlama döneminde kırık meydana gelme riski yüksektir ve erkeklerde kondil kırığı kızlara oranla daha çok görülmektedir. ${ }^{3,4}$ 
Kondil kırıklarında kesin tanıda travmanın hikayesi, klinik muayene ve radyolojik muayene önem taşımaktadır. Hastanın travma sonrası çene ekleminde ağrı, trismus, ağız açılması sırasında deviasyon, asimetri, okluzal bozukluk, açık kapanış varığı klinik bulgular arasınadır. Bu belirtilerle birlikte çene hareketlerinde kondilin palpe edilememesi veya kısmen palpe edilebilmesi tanıyı destekleyicidir. ${ }^{5}$ Pediatrik kondil kırıklarının tedavisi mandibula büyümesine etkisi nedeniyle hala tartışmalı bir konudur. Literatürlerde 3 ana tedavi yöntemi yer almaktadır: Maksillomandibular fiksasyon (MMF) olmadan fizyoterapi, kısa süreli MMF'yi takiben fizik tedavi ve açık redüksiyon ile kırığın internal fiksasyondur.' Kondil kırıklarının tedavisindeki amaç, kırık segmentlerinin redüksiyonu ve stabilizasyonun sağlanıp asimetri ve malokluzyon gelişmesinin önlenmesi ve mandibula fonksiyonlarının minimum travma ile sorunsuz restore edilmesidir. ${ }^{4}$ Çocuklarda özellikle kabul edilebilir okluzyon sağlanarak mandibula fonksiyonlarının ve normal çene büyüme ve gelişiminin devam etmesi amaçlanmaktadır. ${ }^{6,7}$ Kondil kırıklarında diğer kırıklardan farklı olarak, kırık parçaların anatomik redüksiyonun sağlanması şart değildir. Asıl hedef simetrik okluzyon ve fonksiyonun doğru olarak restore edilmesidir. Özellikle çocuklarda redüksiyonun yetersiz olmasına rağmen yenilenen morfoloji ile iyileşmede mükemmel fonksiyon ve okluzyon sağlanabilmektedir.8 Bu nedenle çocuklarda kapalı redüksiyon ilk düşünülen seçenektir. Açık redüksiyon daha çok ciddi dislokasyon, eşlik eden diğer kırıkların varlığı, ağız açıklığının kısıtı olması ve kapalı tedavinin başarısız olması nedeniyle tercih edilir.7 Yanlış ve yetersiz tedavi sonucu yüzde asimetri, kalıcı eklem disfonksiyonu veya ankiloz gelişebilmekte, bu da hastaların ileride açık eklem cerrahisi veya ortognatik cerrahi operasyonları geçirmelerine neden olmaktadır. ${ }^{2}$

Bu olgu sunumunda düşme sonucu çift taraflı deplase subkondiler kııı meydana gelen çocuk hastanın kapalı tedavi ile uzun dönem sonuçları sunularak literatür eşliğinde tartışılması amaçlanmıştır.

\section{OLGU SUNUMU}

İstanbul Medipol Universitesi Ağız, Diş ve Çene Cerrahisi kliniğine başvuran 4 yaşındaki kız çocuğunun anamnezinde evde oynarken koltuktan düştüğü öğrenildi. Klinik muayenesinde çift taraflı posterior erken kapanış, anterior açık kapanış, ağız açmada kısıtııık, temporomandibular eklemde palpasyonda ağrı ve ağız açarken ağrı tespit edildi. (Resim 1a-b).
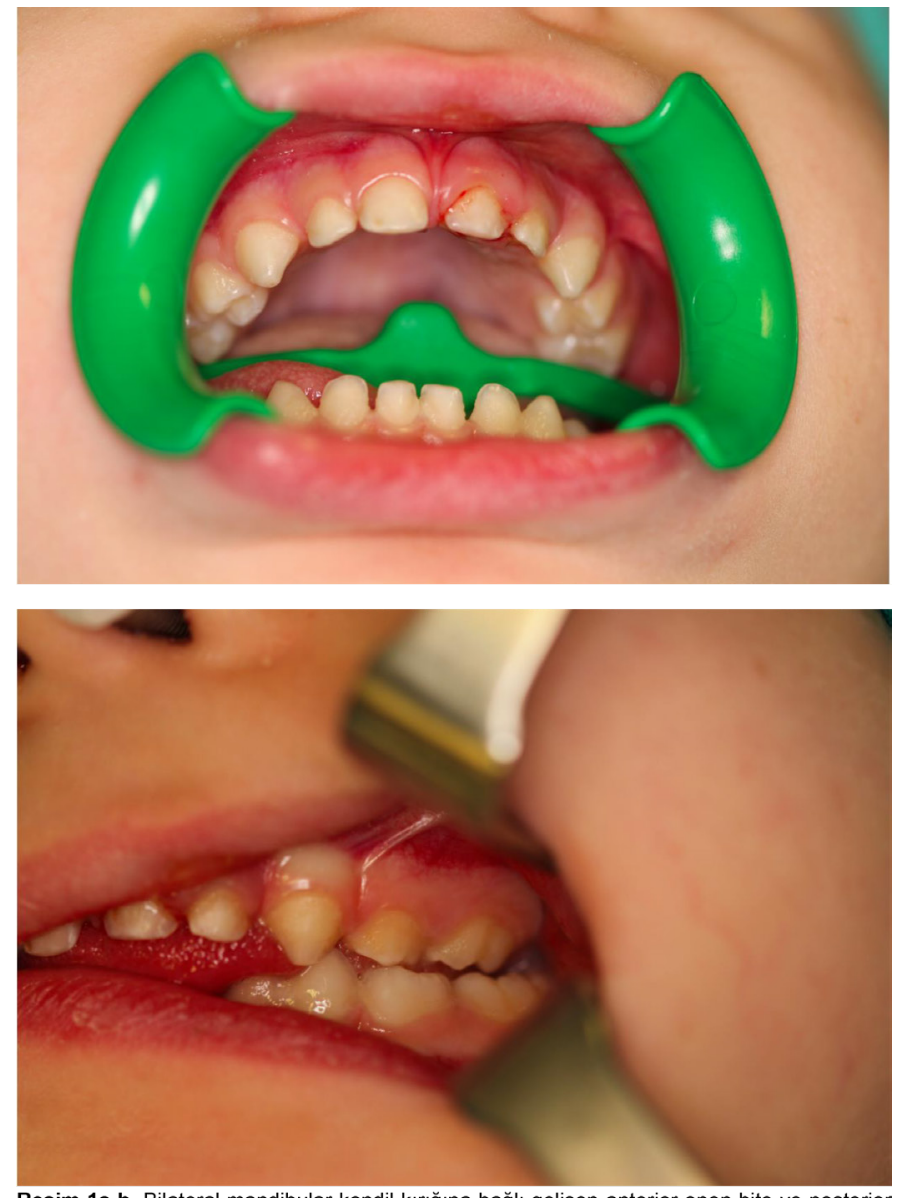

Resim 1a-b. Bilateral mandibular kondil kırığına bağlı gelişen anterior open bite ve posterior erken temas

Ağız açma sırasında deviasyon gözlenmedi. Konik ışınlı bilgisayarlı tomografi ( $\mathrm{CBCT}$ ) ve panaromik grafide izole bilateral mediale deplase subkondiler kırık tespit edildi (Resim 2a-b).

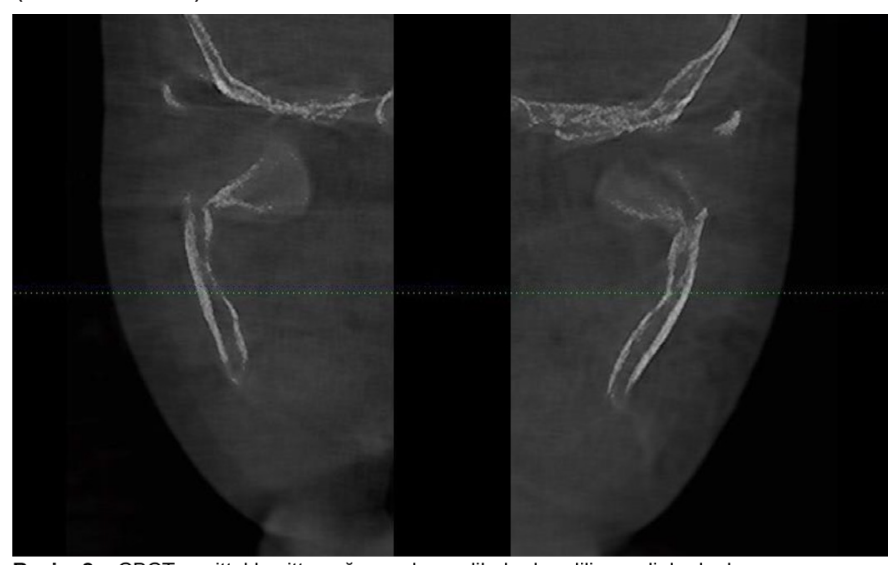

Resim 2a. CBCT sagittal kesitte sağ ve sol mandibular kondilin mediale deplasmanı görülmektedir.

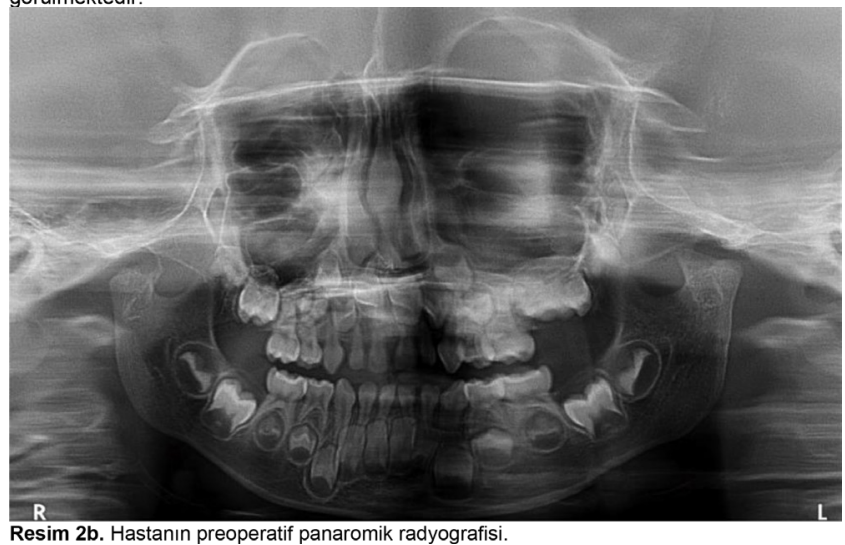


Ağız açıklığının kısıtlı olması, ağı ve kooperasyon güçlüğü nedeniyle hastanın genel anestezi altında tedavisi planlandı. Genel anestezi altında, alt ve üst çeneden aljinat ile ölçü alınarak alt ve üst çenenin alçı modelleri elde edildi. Essix plaktan posterior oklüzyonu $3 \mathrm{~mm}$ yükseltilmiş oklüzal splint hazırlandı ve üst çeneye yerleştirildi. Süt kanin bölgelerine, süt dişinin kökleri ve daimi diş germlerine dikkat edilerek alveol kemiğine transmukozal 4 adet ortodontik mini vida yerleştirildi ve sonrasında elastikler takılarak oklüzyon yönlendirildi (Resim $3 a-b)$.
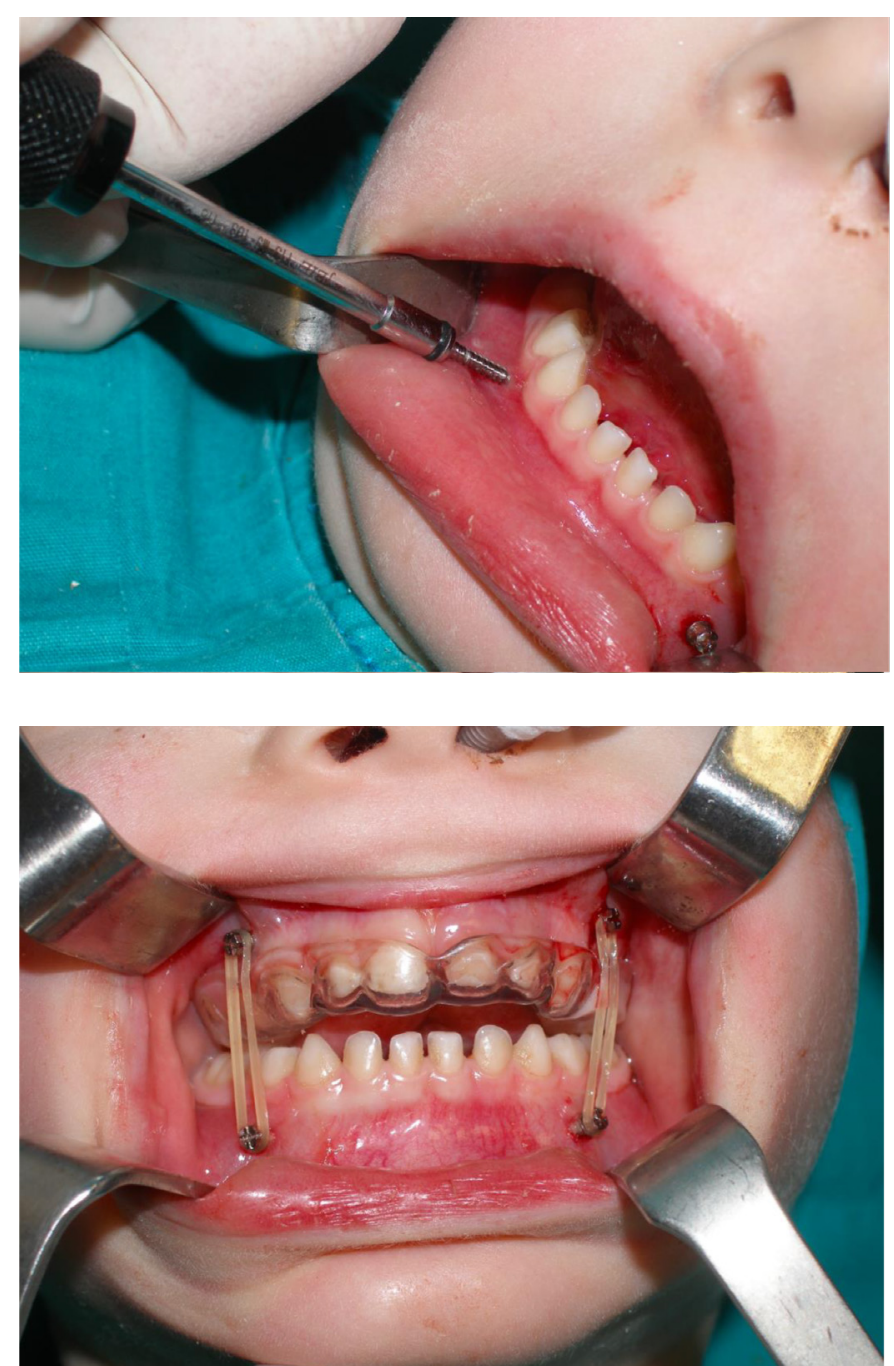

Resim 3 a-b. Transmukozal yerleştirilen ortodontik vidalar ve üst çeneye yerleştirilen Essix plak yardımıyla oklüzyonun yönlendirilmesi

Hastaya postoperatif antibiyotik ve analjezik reçete edildi ve yumuşak diyet önerildi. Hasta haftada bir kez olmak üzere 4 hafta süresince düzenli olarak kontrole çağrıldı. Yapılan oklüzyon kontrolü sonrası plağın yükseltilmiş kısmından mölleme yapıldı. Dört haftalık tedavi dönemi sonrası MMF için kullanılan minividalar ve oklüzyonu yönlendirmek için yapılan Essix plak çıkartıldı. Hastanın 3,5 yılık takibinde herhangi bir komplikasyon, gelişim bozukluğu veya çene hareketlerinde fonksiyon problemi gözlemlenmedi (Resim 4,5).

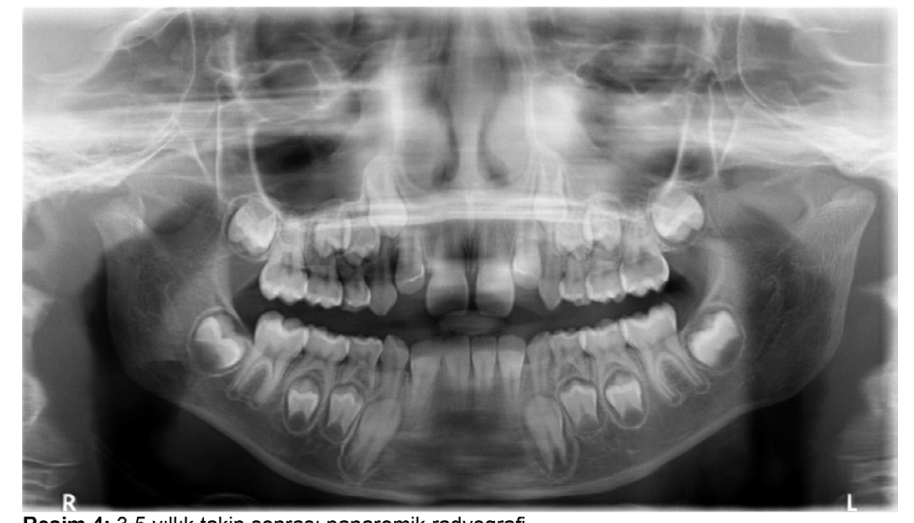

Resim 4: 3.5 yıllık takip sonrası panaromik radyografi

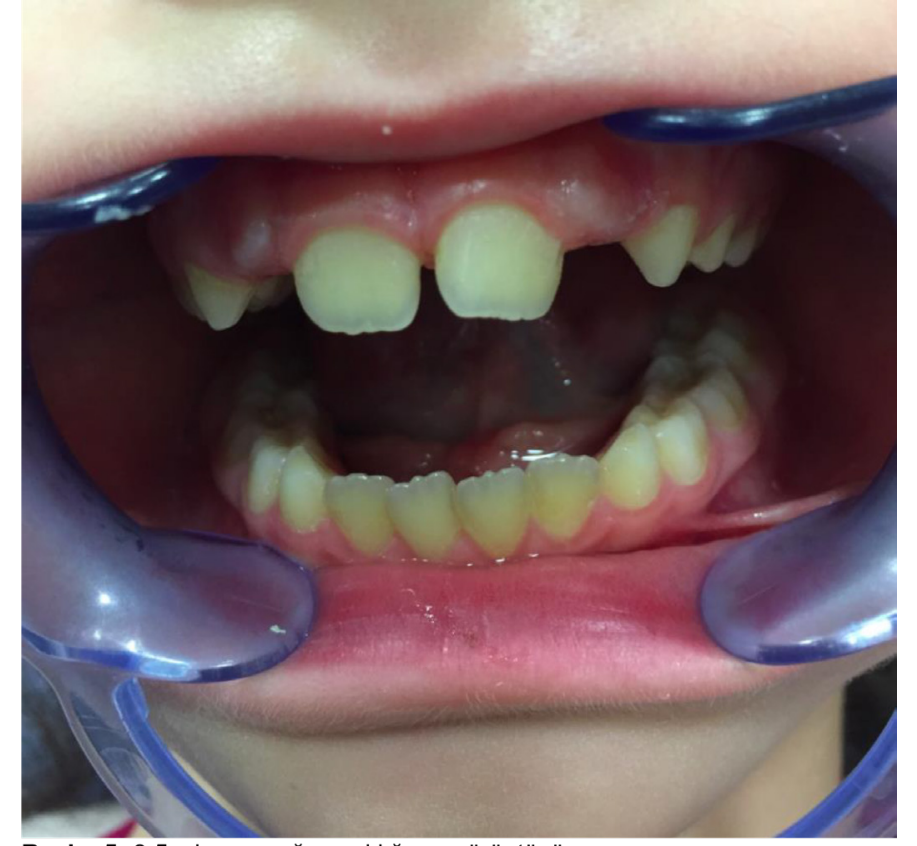

Resim 5: 3.5 yıl sonra ağız açıklı̆ının görüntüsü

TARTIŞMA

Kondil kırıklarının en sık nedenleri, mandibula simfiz ve preauriküler bölgelere gelen travmalardır. Bu bölgeye gelen travmaların kondil vasıtasıyla kafa tabanına iletildiği ve kondilde kırık meydana gelmesiyle kafatabanı kırığının ve böylece beyin travmasının engellendiği düşünülmektedir. $^{9}$

Kondil kırıklarında hastanın yaşının kırığın tipiyle ilişkili olduğunu gösterilmiştir. İki yaş altındaki çocuklarda kısa, iri, vasküler, ince kortekse sahip kondil başı olması nedeniyle intrakapsüler kırık eğilimi vardır. Yaş ilerledikçe kondil boynu daha ince ve uzun hale gelerek kırık eğilimi artar. Bu vaka sunumunda 4 yaşındaki kız çocuğunda bilateral mediale deplase subkondiler kırık meydana gelmiştir.2 Kondil kırıklarının tedavi seçenekleri açık redüksiyon (cerrahi tedavi) ve kapalı redüksiyon (konservatif tedavi) yöntem olmak üzere iki türlü yapılabilmektedir. Genellikle büyük bir kısmı kapalı yöntemle tedavi edilebilmektedir. Çocuklarda cerrahi tedavi endikasyonu yetişkinlere göre daha sınırıdır. ${ }^{9}$ Son dönem çalışmalarda özellikle erişkinlerde açık yöntemle daha az komplikasyon görüldüğü ve başarılı sonuçlar elde edildiği belirtilmiştir. ${ }^{10}$ Tedavi konusunda henüz bir fikir birliğine varılmamış olmasına rağmen; yaş, kırığın yeri ve deformite derecesi tedavi pla- 
nını belirlemede en önemli faktörlerdir. On iki yaş altındaki çocuklarda mandibulanın sahip olduğu yüksek remodeling kapasitesi ile deviye, deplase ve disloke kırıklar kapalı yöntemle tamamen iyileşme ve remodelling göstermektedirler. $^{5}$

Çocuklarda kapalı redüksiyonun açık redüksiyona göre tercih edilmesinin nedenleri arasında diş germlerinin yer alması, kemiğin ince dış kortikal yapısı ve yüksek oranda kansellöz içeriği nedeniyle internal fiksasyondaki güçlükler ve büyüme merkezlerinde meydana gelebilecek hasar yer almaktadır. ${ }^{4}$ Gerek kırık segmentlerinin manüplasyonu gerekse rijit fiksasyon plaklarının yerleştirilmesi nedeniyle büyüme bozukluklarına yol açabilirr.,7 Ayrıca kondil bölgesinin karışık anatomisi, kısıtlı görüş alanı ve nörovasküler açıdan zengin bir bölgede yer alması cerrahi tedavinin zorluklarıdır. ${ }^{8}$ Ancak kapalı tedavinin başarısız olması, eşlik eden diğer kırıklar, ileri derece deplase/disloke kırık varlığı, kırık segmentin mandibula hareketine engel olması, bölgede yabancı cisim varlığı ve kafa tabanında meydana gelmiş kırıklarda açık redüksiyon ve internal fiksasyon tercih edilir. ${ }^{4,7}$

Kapalı yöntem gözlem ve yumuşak diyetten, düzenli peryiotlarda immobilizasyon ve yoğun fizik tedaviye kadar değişen yelpazede tedaviyi içerebilir. Çocuklarda osteojenik potansiyel yüksek olduğundan kırık iyileşmesi de yetişkin hastalardan daha hızlı gerçekleşmektedir. ${ }^{11} \mathrm{Bu}$ nedenle kırıklara mümkün olan en erken zamanda müdahale etmek ve daha kısa süreli immobilizasyon yapmak gerekir. ${ }^{4}$ Kapalı tedavide uygulanan immobilizasyon bazı eklem komplikasyonlarına yol açabilir ve bu erken mobilizasyon yoluyla giderilmeye çalışıır. Erken mobilizasyon yumuşak dokuda sekel oluşumunu azaltır ve eklem hareketliliğini arttırır. $^{12}$

MMF arch barlar, ivy ligatürü, vidalar, braketler veya splintler ile yapılabilir. ${ }^{8}$ Süt dişlerinin kısa kron boyuna sahip olması ya da karışık dentisyonda olmaları nedeniyle eksik, lükse diş varlıkları arch bar ve tellerin kullanımını zorlaştırmaktadır. Braketlerin kullanımı dişlerde harekelenmelere neden olabilmektedir. Titanyum vida kullanımı diş kökleri ve diş germlerine zarar verme riski taşımaktadır. Splintler ise yapımı kolay, atravmatik ve çocuklarda en çok tercih edilen kapalı tedavi apereyleridir. Posterior bölgede yükseltilmiş splintler ile kondil yüksekliğinin ve oklüzyonun istenilen şekilde olması sağlanmaktadır. ${ }^{2}$ Ancak dişlere zarar verebilmesi, bazı çocuklar tarafından tolere edilememesi, oral hijyen problemleri, çürük gelişimi ve besleneme problemlerine yol açması MMF'nin dezavantajlarıdır. Aynı zamanda $\mathrm{MMF}^{\prime}$ nin uzun süre uzun süre uygulanması ankiloz riskini arttırmaktadır. Bu yüzden konservatif ve fonksiyonel tedavi daha çok kabul görmektedir.11

Arita 10 yaş ve altındaki çocuklarda unilateral veya bilateral kondiler kırıkların tedavisinde MMF yerine aktivatör kullanılarak yapılan fonksiyonel tedavinin çok etkili so- nuçlar sağladığını göstermiş ve 7 ay sonunda remodeling ile kondilin fossa içinde tamamen normal morfolojide olduğunu belirtmiştir. ${ }^{13}$

Klasik fonksiyonel tedavi "form foksiyonu takip eder" esasına dayanmaktadır. ${ }^{2}$ Fonksiyonel tedavide her çocuğa yaşa, mandibulanın gelişim seviyesine, kırık seviyesine ve deplasman derecesine göre farklı kalınlıkta ve değişik sürelerde splint uygulanması önerilmektedir. Daha küçük çocuklarda, yüksek seviye deplase kondil kırıklarında 2 mm kalınlığında splint kullanıırken; daha büyük çocuklarda, düşük seviye deplase kırıklarda 3-4 mm kalınlıkta plakların daha uzun kullanımı önerilmiştir."1

Kondil kırıklarının klinik değerlendirmesinde normal interinsizal açıklık, deviasyon gözlenmeden çene hareketlerinin yapılabilmesi, kabul edilebilir okluzyon ve subjektif bulguların olmaması ana kriterler olarak belirtilmiştir. ${ }^{7}$ Güven ve Keskin de maksimum interinsizal açıklığın, takiplerde eklem foksiyonlarını değerlendirmede iyi bir indikatör olduğunu rapor etmiştir. ${ }^{14}$ Yaş, kırığın lokalizasyonu ve derecesi, eşlik eden kırıklar gibi bazı değişkenler tedavi sonucunu etkilemektedir. Ancak sekeller ve değişkenler arasındaki ilişki kesin değildir.7 Komplikasyonlar disloke ve düşük kondil kırıklarınlarında daha sık görülse de15 bu olguda deplase subkondiler kırık mükemmel bir şekilde iyileşmiş ve herhangi bir komplikasyona rastlanmamıştır Bilateral deplase kondil kırıklarında ramus boyundaki kısalma eğilimi artmakta, posterior dişlerde primer kontakt meydana gelerek ön açık kapanış oluşmaktadır. Kapalı yöntemle tedavi edilen bilateral kondiler kırıklarda özellikle büyüme gelişme bitene kadar uzun süreli sıkı takip önemlidir. İyi bir okluzyon ve eklem foksiyonu için daha uzun süreli elastik kullanımı ve daha çok dişsel adaptasyon gerekmektedir. ${ }^{2}$ Gupta ve ark. ${ }^{16}$ bilateral kondil kırılarından sonra unilateral kondil kırıklarına göre daha ciddi komplikasyonlar olduğunu iddia etmişlerdir. Ancak Lekven ve arkadaşları tek taraflı kondil kırığının bilateral kırıklara göre istatistiksel olarak anlamlı ölçüde yüksek istenmeyen klinik sonuçlara neden olduğunu rapor etmiştir. ${ }^{17}$ Kapalı yöntem sonrası kondilin yeniden şekillenmesi çeşitli çalışmalarda araştırımıştır. Lekven ve arkadaşlarının yapmış olduğu radyolojik çalışmada konservatif tedavi ile \%87 üzerinde tam bir remodeling görüldüğü bildirilmiştir. ${ }^{17}$ Başka bir çalışmada 3-12 yaşları arasındaki çocukların yetişkin ve gençlere kıyasla yüksek oranda kondiler rejenerasyon ve şekillenme potansiyeli olduğu belirtilip, çocuklarda normal kondil fossa ilişkisinin travmadan sonra 2-3 yıl içinde oluştuğu gösterilmiştir. ${ }^{18}$ Kapalı yöntem uygulanan hastalarda yetersiz remodeling kapasitesinin olması bifid kondil oluşumuna, ankiloza, fasiyal deformiteye neden olabilmektedir. ${ }^{2}$

Çalışmalar çocuk ve gençlerde disloke kondil kırıklarında hem cerrahi hem de konservatif tedavinin sonuçlarının memnun edici olduğunu göstermektedir. ${ }^{6}$ Ancak kondil 
kırıkları için farklı sınıflandırma yöntemlerinin kullanılıyor olması ve sınıflama güçlüğü (ortak kullanılan ve üzerinde uzlaşmış bir sınıflama olmayışı) açık ve kapalı tedavi sonuçlarının karşılaştırıımasında zorluk yaratmaktadır. ${ }^{19}$

\section{SONUÇ}

Bu olguda posteriorda erken temas ve önde açık kapanışın düzeltilmesi amacıyla normal okluzyon yükseltilmiş essix plaklar ve elastik yönlendirmeler ile sağlanmıştır. Yumuşak diyet, erken fizik tedavi ve sıkı takip ile kondilin yeniden sekillenmesi sağlanıp ramus yüksekliği korunmuş ve ankiloz önlenmeye çalışı recesi artıkça cerrahi tedavi seçeneğine doğru eğilim artmasına rağmen küçük yaş grubundaki hastalarda kapalı redüksüyon ile oldukça başarılı sonuçlar alınmaktadır.

\section{KAYNAKLAR}

1.Ghasemzadeh A, Mundinger GS, Swanson EW, Utria AF, Dorafshar $\mathrm{AH}$. Treatment of pediatric condylar fractures: $\mathrm{A}$ 20-year experience. Plast Reconstr Surg 2015; 136: 1279 1288.

2.Zhou H, Han J, Li Z. Conservative treatment of bilateral condylar fractures in children: Case report and review of the literature. International Journal of Pediatric Otorhinolaryngology. 2014; 78: 1557-1562.

3.Marana R, Neto PO, Sakugawa KO, Zanetti LSS, Moraes $M$. Mandibular fractures in children under 3 years: A rare case report. Rev Port Estomatol Med Dent Cir Maxilofac 2013; 54: 166-170.

4.Özgenel GY, Özbek S, Kahveci R, Akın S, Özcan M. Pediatrik mandibula kırıkları. Türk Plast Rekonstr Est Cer Derg 2004; 12: 21-24.

5.Markal N, Çelebioğlu S. Mandibula kondil kırıkları ve tedavi yaklaşımları. Ankara Üniversitesi Tıp Fakültesi Mecmuası. 2000; 53: 39-42.

6.Shi J, Chen Z, Xu B. Causes and treatment of mandibular and condylar fractures in children and adolescents: A review of 104 cases. JAMA Otolaryngol Head Neck Surg 2014; 140: 203-207.

7.Zhao Y, Yang J, Bai R, Ge L, Zhang Y. A retrospective study of using removable occlusal splint in the treatment of condylar fracture in children. J Craniomaxillofac Surg 2014; 42: 1078-1082.

8. Kısa Hİ, Tatlı U, Kürkcü M. Mandibular kondil kırıkları ve tedavi yöntemleri. Arşiv Kaynak Tarama Dergisi 2014; 23: 659-673.

9.Cucurullo R, Giannuzzi I, Clivio A, Biagi R. Management of unilateral condylar fracture in a 9.6-year-old female. Eur J Dent 2009; 10: 95-101.

10.Berner T, Essig H, Schumann P, Blumer M, Lanzer M, Rucker M, Gander T. Closed versus opened treatment of mandibular condylar process fractures: A meta-analysis of retrospective and prospective studies. J Craniomaxillo- fac Surg 2015; 43: 1404-1408.

11.Zhao Y, Zhang Y. Condylar fracture in children: Current knowledge and considerations. JSM Dent 2016; 4:1059.

12.Büyükakyüz N, Öğüt $M$, Uyumaz N, Öztürk M. Alt çene kondil kırıkları ve tedavi yöntemleri. İst Üniv Diş Hek Fak Derg 2010; 44: 55-61.

13. Arita K. Functional treatment of condylar process fractures in children. J Hard Tissue Biology 2005; 14: 51-52. 14.Güven $O$, Keskin A. Remodeling following condylar fractures in children. Journal of Craniomaxillofac Surg 2001; 29: 232-237.

15.Thoren $H$, lizuka $T$, Hallikainen $D$, Lindqvist C. Radiologic changes of the temporamandibular joint after condylar fractures in childhood. Oral Surg Oral Med Oral Pathol Oral Radiol Endod 1998; 86: 738-745.

16.Gupta M, lyer N, Das D, Nagaraj J. Analysis of different treatment protocols for condylar process of mandible. J Oral Maxillofac Surg 2000; 70: 83-91.

17.Lekven N, Neppelberg E, Tornes K. Long-term follow-up of mandibular condylar fractures in children. J Oral Maxillofac Surg. 2011; 69: 2853-2859.

18.Dahlstrom L, Kahnberg KE, Lindahl L. 5 years follow-up on condylar fractures. Int $\mathrm{J}$ Oral Maxillofac Surg 1989; 18: 18-23.

19.Köybaşı S, Biçer YÖ, Korkmaz T, Şimşek T. İki taraflı alt çene kondil kırığı: Olgu sunumu. Kulak Burun Boğaz Uygulamaları. 2014; 2: 73-77. 